\title{
Unpacking action research and implementation science: Implications for nursing
}

\author{
Mary Casey \\ University College Dublin \\ Denise O'Leary \\ Technological University Dublin, denise.oleary@tudublin.ie \\ David Coghlan \\ Trinity College Dublin, Ireland
}

Follow this and additional works at: https://arrow.tudublin.ie/tfschhmtart

Part of the Medical Education Commons, and the Nursing Commons

\section{Recommended Citation}

Casey, M, O' Leary, D, Coghlan, D. Unpacking action research and implementation science: Implications for nursing. J Adv Nurs. 2018; 74: 1051- 1058, DOI: 10.1111/jan. 13494

This Article is brought to you for free and open access by the School of Tourism \& Hospitality Management at ARROW@TU Dublin. It has been accepted for inclusion in Articles by an authorized administrator of ARROW@TU Dublin. For more information, please contact arrow.admin@tudublin.ie, aisling.coyne@tudublin.ie, gerard.connolly@tudublin.ie.

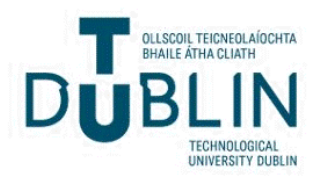




\section{Unpacking action research and implementation science: Implications for nursing}

\section{Mary Casey ${ }^{1}$ (D) | Denise O' Leary ${ }^{2}$ | David Coghlan ${ }^{3}$}

\author{
${ }^{1}$ UCD School of Nursing, Midwifery \& \\ Health Systems, University College Dublin, \\ Belfield, Ireland \\ ${ }^{2}$ School of Hospitality Management and \\ Tourism, Dublin Institute of Technology, \\ Dublin, Ireland \\ ${ }^{3}$ Trinity Business School, Trinity College \\ Dublin, Dublin, Ireland

\section{Correspondence} \\ Mary Casey, UCD School of Nursing, \\ Midwifery \& Health Systems, University \\ College Dublin, Belfield, Ireland. \\ Email: Mary.Casey@ucd.ie
}

\author{
Abstract \\ Aim: The aim of this study was to unpack the key concepts of action research and \\ implementation science thereby enabling appropriate use of these methods in \\ nursing.
}

Background: A key issue in action research is not so much the methodology employed to gather data/evidence but who decides the research agenda and who benefits from it. Implementation science is a way to ensure that evidence is translated into practice. The question arises as to how action research and implementation may be understood in relation to one another in nursing.

Design: Discussion Paper

Data sources: This discussion paper is based on our own experiences and offers an exploration of action research and implementation science with the aim of clarifying what each involves and what synergies, if any, exist between them.

Implications for Nursing: Using action research to secure the voice of patients in their own care is essential to delivering quality nursing care. Using implementation science frameworks to get research evidence into practice is effective. Familiarity with both these concepts may enable their improved use and have a positive impact on quality of care.

Conclusion: There is a tension between action researchers and the protagonists of implementation science related to perceived "trade offs" between what constitutes "science" and the necessity of community participation. Nevertheless, the use of an implementation science framework in an action research approach can reduce the research practice time lag and action research provides sound theoretical and philosophical underpinnings that can be used by those in the implementation science field.

\section{KEYWORDS}

action research, evidence-based practice, implementation science, nursing practice

\section{1 | INTRODUCTION}

The presence of gaps between knowledge and practice is well documented and both action research and implementation science attempt to overcome this. Action researchers are looking to close the culture gap and close the distance between researcher and practitioner. Implementation science is considered the way to ensure that research evidence is translated into practice. In that regard implementation science emphasizes the implementation element than on its contribution to knowledge creation. In comparison, action research attempts to give consideration to both the action and the research element of that action. 
Action research has its origins in Aristotelian praxis, pragmatic philosophy, phenomenology, constructivism, Lewinian social psychology and finds expression in several modalities, such as action science, appreciative inquiry and clinical inquiry/research (Coghlan, 2011). Action research works within an extended epistemology and seeks to generate practical knowledge in the present tense through cycles of constructing, planning, taking action and evaluating action (Coghlan \& Shani, 2017). In its original form, action research consists of cycles of planning, action and fact-finding, preceded by a pre-step (Lewin, 1997; Lewin 1946). The pre-step consists of articulating an objective and reconnoitring the situation. Planning involves developing a project plan and a decision regarding the first step. Taking action starts with taking that step and fact finding is concerned with evaluating learning and to ensure that the next cycle builds on the positive and addresses any issues. So there is a continuing "spiral of steps, each of which is composed of a circle of planning, action and fact-finding about the result of the action" (Lewin, 1997 p.144).

Implementation science originated from practice-based evaluations in relation to health care that were undertaken in the $1960 \mathrm{~s}$ and 1970s to understand problems with the implementing national initiatives in the United States (Lobb \& Colditz, 2013). It is defined as "the scientific study of methods to promote the systematic uptake of research findings and other evidence-based practices into routine practice and, hence, to improve the quality and effectiveness of health services and care" (Eccles \& Mittman, 2006:1). It is more concerned with practical implementation than theoretical foundations although, according to Nilsen (2015 p.1) implementation science acknowledges "the need to establish the theoretical bases to facilitate implementation" and as such there is "mounting interest in the use of theories, models and frameworks to gain insights into the mechanism by which implementation is more likely to be successful".

This discussion paper is based on our own experiences and offers an exploration of action research and implementation science with the aim of enabling nurses to understand both methods and to draw on the more appropriate approach or combination of approaches to facilitate getting evidence or a change into practice. Each of the three authors have extensive experience in undertaking action oriented research projects at international, national and local level. In addition, we have supervised $\mathrm{PhD}$ and Masters nursing, medicine and allied health students undertaking change initiatives. The majority of those students have used action research but some have used implementation science. These projects include the development and implementation of various patient assessment tools across different clinical areas, the implementation of standards of care in a variety of clinical, rehabilitation and long term care settings, supporting informed choice for clients and patients and developing new work practices and procedures.

Our experience has highlighted that there is some confusion among researchers and participants about the two approaches. Thus, in this paper, we will explore the features of action research and implementation science, as well as the lessons we have learnt from our experience with both approaches.

\section{Why is this research or review needed?}

- Getting research evidence into practice for a more effective and sustainable healthcare service is critical for nurses. Consequently, nurses need to be familiar with action research and implementation science.

- Nurses should be informed of the application of action research and implementation science framework in context of ensuring the voice of the patient has currency when translating evidence based practice into quality care

- This paper offers new insight into the benefits of using an implementation science framework as part of an overall action research approach when considering how to improve patient care

\section{What are the key findings?}

- The use of an implementation science framework within an action research approach can reduce the research practice time lag.

- As action research incorporates a process approach towards implementation, it has the potential to address some deficits in implementation science

- Implementation science focuses on implementing research evidence in healthcare practice and policy-making while action research has a broader focus on what is researched and for whom, who creates what is researched and how those most affected are codesigners, co-implementers, co-evaluators, in short, are co-researchers in the entire process.

\section{How should the findings be used to influence policy/practice/research/education?}

- The presence of gaps between knowledge and practice is well documented and a range of approaches such as action research and implementation science attempt to address this

- Implementation and evaluation should be considered in the research design as well as the inclusion of end-users. These concepts are embodied in action research. Hence implementation science could benefit from an action research process approach.

- In the context of nursing care getting the "tried and tested" evidence into practice becomes imperative particularly if the anticipated outcome is a clinical improvement in patient care. Therefore, the more that is learnt about the process of implementation, the more likely it is that implementation will be successful. 


\section{1 | Background}

Action research is an approach to research which aims at both taking action and creating knowledge or theory about that action. Torbert (1991 p.220) refers to action research as "a kind of scientific inquiry conducted in everyday life". The outcomes are in the realms of both action and research, unlike traditional research approaches where action is not an aim and creation of knowledge is the focus. Greenwood (2007 p.131) provides the following definition:

Action research is neither a method or a technique; it is an approach to living in the world that include the creation of areas for collaborative learning and the design, enactment and evaluation of liberating actions. . .it combines action and research, reflection and action in an ongoing cycle of co-generative knowledge.

At the core of action research is a participatory worldview that asks human persons to be both embedded and reflexive, to be explicit about the perspective from which knowledge is created, to see inquiry as serving what Reason and Torbert (2001 p.3) refer to as the "the flourishing of human persons, communities and the ecologies of which they are part". A primary purpose of action research is the production of knowledge that is both useful and practical in everyday life (Coghlan, 2016).

Action research not only seeks to generate practical knowledge it also includes the creation of areas for collaborative learning where the research is with, rather than on or for people and the people are co-researchers and co-inquirers rather than subjects. In this sense, it is a liberating action and challenges traditional science in several ways. Because power is shared with participants the existing status quo, which places knowledge and policy development firmly in the domain of researchers and policymakers, is subverted. There is an epistemological assumption in action research that research should not only describe, understand and explain the world but also change it (Reason \& Bradbury, 2008). Accordingly, a core value of the participative nature of action research is that the co-researchers and coinquirers co-design, co-implement and co-evaluate. Therefore, action research should be judged using the epistemological and ontological foundation of action-based research rather than through the lens of the positivist paradigm. Thus, as Levin (2003) argues, action research contributes to scientific discourse in a unique way due to its solutions-focused emphasis on co-generation of meaning and knowledge, participatory action and real problems encountered by participants.

\subsection{Varieties and prevalence of action research}

Action research has grown, since its emergence in the 1940s, into a family of approaches, each of which is linked to a particular scholar and which places emphasis on a particular context or practice within the broad value system described above, for instance, action science, appreciative inquiry, cooperative inquiry, learning history (Coghlan, 2010). Selecting a modality in a given situation requires insight into not only the modality itself but also to what might be required to inquire rigorously in a given situation (Coghlan, 2010).

The growing prevalence of action research appears to be related to the inability of positivism to embrace the social context where people mutually construct meaning and also to the way positivism regards participants as passive subjects. Williamson and Prosser (2002) claim the increased application of action research in healthcare settings has to do with the failure of the biomedical approach to provide solutions in the health and illness context. Morrison and Lilford (2001:448) advocate action research methodology in the health services stating that "as health services present a highly constrained environment for the researcher, some of the ways of working pioneered by action research could, if adopted by mainstream researchers, make their findings more readily useable by health care professionals and managers". An advantage of using action research in healthcare practice is that action research goes beyond a description towards implementation as it brings together action and reflection, theory and practice, in participation with others, to find solutions that are of mutual concern to those involved and to generate actionable knowledge (Coghlan \& Casey, 2001).

\section{3 | Implementation science}

Implementation science focuses on promoting the systematic uptake of research into healthcare practice (Eccles \& Mittman, 2006; Nilsen, 2015). Acknowledging the gap between what is established to improve patient care and what is used in daily practice, has led to the expanding interest in knowledge translation and particularly in the ways action can be enhanced by practitioners. Implementation science is a practical approach to understanding, reflecting on and evaluating project planning and implementation (Babbie, 2013; Rycroft-Malone et al., 2013). In creating this understanding of the implementation process the evaluation can provide contextually rich information on if and how evidence is implemented in practice (Damschroder \& Lowery, 2013; Kitson et al., 2008; Rycroft-Malone et al., 2004). Therefore, implementation science needs to be understood as a non-linear continuous, interactive process, involving "agents" (May, 2013), working within a "context" (Rycroft-Malone et al., 2013) to facilitate improvement.

\section{4 | Origins of implementation science}

According to Green, Glasgow, Atkins, and Stange (2009) the need for organizational accountability and the need to ensure that policies were implemented as planned, particularly in healthcare contexts, led to the emergence of implementation science. A goal of implementation science for health is to "identify the factors, processes and methods that successfully embed Evidence Based Interventions in policy and practice to achieve population health" (Lobb \& Colditz, 2013:237). Essentially implementation science attempts to understand how practice interventions which are tested in a controlled setting can be implemented across a broader spectrum of settings (Nilsen, 2015). Research emphasis on the clinical healthcare practice 
paradigm, of necessity must focuses on what can be standardized and controlled to enhance reproducibility. This "serves as the gold standard for health services research ...the branch of health care research where implementation science was first cultivated" (Sobo, Bowman, \& Gifford, 2008 p.1531). It is to be expected therefore that in more recent times, the focus of implementation science has focused more on ways to accelerate the translation of researchtested interventions into policy and practice within "complex adaptive systems" (Best, 2011 p.eix). This would hasten implementation of discovery research for use by decision makers not only in specific practice settings but also in more widespread clinical healthcare contexts. Influencing factors on the use of evidence in practice relate to characteristics of the intervention (cost), research design such as participants that are non-representative of the target population, research context and culture of the practice setting (Glasgow \& Emmons, 2007).

Another focus of implementation science is to address the information gap along the research-to-practice continuum as guidelines are needed to enable practitioners and decision-makers to apply and evaluate the use of evidence based initiatives across populations and different settings. Because of its nascent status, implementation science has not touched on this area. Whereas there are many examples of action research being used to simultaneously introduce change as well as guidelines to govern the new procedure. Moreover, improved use of evidence-based interventions through participatory research will expedite the use of these innovations by the inclusion of policy and practice stakeholders (Lobb \& Colditz, 2013). Sobo et al. (2008 p.1531) suggests that implementation science "assumes that the best way to deal with real-world contingencies is to bring them into the research process, for example by incorporating participatory research strategies". Action research is not mentioned along the stakeholder engagement continuum (Lobb and Colditz (2013), instead statistical modelling to evaluate possible outcomes of an intervention is placed at the lower end, with pragmatic trials somewhere towards the centre and formal partnerships between researchers and those in practice at the higher end of the continuum.

Incorporation of systems thinking from an organizational context and providing measures of establishing external validity is difficult in Implementation Science. Green (2008) suggests that because of the contextual nature of research a perfect solution to external validity may not be possible although Lobb and Colditz (2013) argue that improved reporting on external validity to provide better practice based evidence and relevance of research to practice is necessary.

Implementation science can also be used to review major bottlenecks that impede implementation and to understand and evaluate the process thereby optimizing enactment. In this way, barriers can be anticipated and a comprehensive knowledge of the intricacies of implementation and a more likely method of execution can be advanced (Damschroder et al., 2009). Over the last two decades, the theoretical basis of implementation and strategies to facilitate implementation has improved and while implementation science is a relatively new field, its use in health care is supported at an international level by the World Health Organisation which has called for increased implementation of evidence in decision making at practice and policy level and suggested that implementation research is a means of achieving this aim (Peters, Tran, \& Adam, 2013). Therefore, its purpose is also to learn from the implementation process and to determine frameworks that signal how implementation may be improved, or indeed rolled out to other contexts.

\section{5 | Implementation science frameworks}

Implementation science can be viewed as part of a diffusion- dissemination -implementation continuum (Nilsen, 2015), where diffusion is seen as passive and untargeted communication of evidencebased practices, dissemination is the more active and planned spread of information to targeted audiences and implementation is the process of integrating new practices into a clinical setting. Many theories, models and frameworks have been used to gain insight into the factors that constitute success or failure of implementation. Many have emerged from within implementation science while some theories have emerged from psychology, sociology and organization theory (Nilsen, 2015). Early implementation research was empirically driven and paid little attention to the theoretical underpinning of implementation (Nilsen, 2015). According to (Nilsen, 2015), there are five categories of theoretical approaches used in implementation science namely:

1. Process models - such as Quality Implementation Framework, Ottawa model for research utilisation

2. Determinant frameworks such as PARIHS (Promoting Action on Research Implementation in Health Services) and CFIR (Consolidate framework for implementation research)

3. Classic change theories such as organizational culture, leadership and organizational learning

4. Implementation theories such as normalization process theory

5. Evaluation frameworks such as Re-Aim (Reach, Effectiveness, Adoption, Implementation, Maintenance)

While frameworks have a descriptive purpose and theories may have some predictive capacity and models can be used to describe and guide a process, in truth "neither models nor frameworks specify the mechanisms of change; they are typically more like checklists of factors relevant to ...implementation." (Nilsen, 2015:3). Classic change theories are also criticized for their passivity in relation to action models on the basis that while they describe and explain how change occurs they are "without ambitions to actually bring about the change" (Nilsen, 2015 p.7).

The PARiHS framework represents one of the first multidimensional frameworks to capture the complexity of implementing evidence-based practice, linking evidence, context and facilitation (Rycroft-Malone et al., 2004). It emerged from the acknowledge that the characteristics of the evidence, the context and facilitation process could have an impact on successful implementation in health care. 
May (2006) developed another model for assessing and evaluating complex interventions in health care. This model used four domains, namely: "interactional workability", "relational integration", "skill-set workability" and "contextual integration", with the aim of understanding how new methodologies and particularly new technologies, became embedded in health care. This lead to the development of a theory of action, called the Normalization Process Theory in 2009 (May \& Finch, 2009). This process theory explained how new thinking became embedded into health care. It specifically explored implementation and change with reference to the role of change agents (May \& Finch, 2009).

Damschroder et al. (2009) describe the "Consolidated Framework for Implementation Research" (CFIR). This promoted a more universal implementation theory focusing on factors have an impact on successful implementation across multiple contexts. This framework listed the five domains - intervention characteristics, outer and inner settings, traits of the individuals and the process for implementation. Within these five domains, there are 37 constructs and sub-constructs. Eight constructs were additionally identified related to the intervention such as evidence of strength and quality, adaptability, four related to the outer setting such as patent needs and resources, 12 constructs relate to the inner setting such a culture and leadership, five constructs relate to the individual characteristics and eight constructs relate to the implementation process such as planning, evaluating and reflecting.

These constructs can be used as implementation and evaluation criteria to structure analysis around the impact of processes on outcomes. The idea behind CFIR was to: "help advance implementation science by providing consistent taxonomy, terminology and definitions on which a knowledge base of findings across multiple contexts can be built" (Damschroder et al., 2009 p.2). There is acknowledgement that adaptation is part of the model as "without adaptation, interventions usually come to a setting as a poor fit, resisted by individuals who will be affected by the intervention and require an active process to engage individuals to accomplish implementation" (Damschroder et al., 2009 p.3). To complement its use, a "process" or "action theory" is needed - and action research could easily accomplish this requirement. Nilsen (2015) acknowledges that there is some overlap between these five categories and suggests that a single theory that focuses on single aspect of implementation will not provide the full picture and suggest that combining multiple theoretical approach may offer a more complete understanding. In a review of the literature on the use of the CFIR, Kirk et al. (2016) highlighted its use in several contexts, but suggested that justification for its use should be provided by the researchers. They argue that a more in-depth use of this and other frameworks is needed to advance the field of implementation science.

\section{DISCUSSION}

The question arises as to how action research and implementation science may be understood in relation to one another within the context of action-oriented research approaches in health care. One point of divergence between the approaches is that implementation science focuses on implementing existing research evidence in health care practice and policy-making. Action research can be used to implement existing evidence but also has a broader focus and can entail developing as well as implementing evidence. It is also more useful in contexts where there is conflicting or unclear research evidence as those most affected are co-researchers in the process.

The element of stakeholder participation which is a crucial component of any action research project does not receive the same attention in implementation science. Yet, our experience suggests that success is often dependent on the inclusion of key stakeholders in the design process rather than the comprehensiveness and application of any particular framework. Green and Glasgow (2006) suggest that such participatory research requires continuous two-way communication between researchers and stakeholders to explore the needs of those in practice and the development of interventions for a better fit with reality. Action research approaches, are predicated on involving stakeholders as participants rather than subjects in research (Reason \& Bradbury, 2008). Implementation science is seen as more directly influencing knowledge translation but when knowledge translation is defined as "the exchange, synthesis and ethically sound application of knowledge to improve health and provide more effective health services" (Thomas, Menon, Boruff, Rodriguez, \& Ahmed, 2014:1), we suggest that action research can assist this process due to its emphasis on participation, inclusivity and cogeneration of knowledge. Indeed, we have found over the course of undertaking and supervising research projects, that implementation science frameworks are useful tools in designing and implementing change initiatives but that inclusion of participants is a key element in successful change initiatives.

Another difference between action research and implementation science is that action research aims to create and/or add to existing theoretical and practical knowledge, something which does not appear as an overt objective in implementation science. Yet our experience, as researchers as supervisors, in the co-creation and dissemination of knowledge has highlighted for us the importance of this activity. Theoretical frameworks that emerge from action research projects can be interrogated and augmented by others, thus providing a theoretical scaffold for further knowledge creation.

Implementation science is defined as the scientific study of approaches to promote the systematic uptake of research findings and other evidence-based practices (EBP) into practice and is sometimes presented as the "parent" of all approaches to promote change and translation of evidence based research to practice particularly by those not aware of the chronology of development of these two broad concepts. From the perspective of action research, implementation is only one step in the cycle and can only proceed consequent to constructing and planning, be followed by evaluation and be the basis for enacting further cycles. From our perspective action, research is the "parent" approach as it begins with the experience of context, the questions which arise, how these questions are constructed as meaningful and relevant, what actions are planned, taken and evaluated. 
The presence of gaps between knowledge and practice is well documented and a range of approaches such as action research and implementation science attempt to address this. Herein lies another source of tension between these two concepts - particularly where science is seen as cold, straight, detached and having certainty and research as warm and risky (Latour, 1998 cited in Nowotny, Scott, \& Gibbons, 2001). While there continues to be some debate as to what we might mean by "scientific" in the realm of action research, on the surface the use of the term "implementation science" suggests a scientific method in comparison to the term "action research", a view that has no substance (Argyris, Putnam, \& Mclain Smith, 1985; Cassell \& Johnson, 2006; Coghlan, 2011; Susman \& Evered, 1978). The value of researching the implementation process while the process is ongoing through action research can sometimes be interpreted as non-scientific, simply because it is seen as moving away from the planned research approach and into the more subjective process. In this context, getting the "tried and tested" evidence into practice becomes imperative particularly if the anticipated outcome is a clinical improvement in patient care. In our experience, the more that is learnt about factors that influence the process of implementation, the more enlightened are those attempting to implement the process. In the past, frameworks for change management denoted the broad organizational and sometimes process issues to consider when planning change. Implementation science in many ways constitutes the new change management framework and this is the value these frameworks add to implementing evidence-based practice. However, these frameworks say little about the process itself. This is where action research as a process methodology complements all frameworks for change management -regardless of context (Whitehead, 2005). Thus, implementation science focuses on implementing research evidence in healthcare practice and policy-making while action research has a broader focus on what is researched and for whom, who creates what is researched and how those most affected are co-designers, co-implementers, co-evaluators, in short, are co-researchers in the entire process.

Because of this broader focus, attention has been given in the action research literature to issues that have been acknowledged in implementation science but not explored in detail. For example, it has been acknowledged that reflection by individuals on their practice should be an essential component of implementing evidencebased changes (Melynk \& Fineout-Overholt, 2011), but it is in the action research literature that reflection within the process of introducing changes in clinical practice has been explored in detail. Similarly, attention has been given to ethics in the action research literature where it has been highlighted that existing positivist-based ethical guidelines do not sufficiently address the complexity of the action research process, described (Coghlan \& Shani, 2005). Accordingly, ethical guidelines which take into account the complexity of doing research with rather than on people, but which also prioritize the rights of participants and concern for their well-being, have been developed (Brydon-Miller, 2012). These guidelines could be equally relevant to implementation science. In practice, we have found that students taking an action research approach have benefited from the frameworks developed in implementation science and similarly students taking and implementation science approach have been found integration of the participatory, reflective and ethical principles underpinning action research to be invaluable.

Reason and Bradbury (2008) contend that action research appeals to researchers who wish to make positive changes in the world. The same is true of those undertaking implementation science since in health care, both approaches are usually concerned with implementation of changes in practice. However, there is some confusion in the literature as to how the two research approaches relate to each other. Some authors describe the integration of participatory action research (PAR) approaches into implementation science projects (Bailie, Matthews, Brands, \& Schierhout, 2013; Goodyear-Smith, Jackson, \& Greenhaigh, 2015). Others take an action research approach but draw on theoretical frameworks from the implementation science field (Breimaier, Halfens, \& Lohrmann, 2015; Brown \& McCormack, 2011; Heyrani et al., 2012; Murphy, 2015). As highlighted earlier, action research is not a single approach but a family of approaches, yet in the implementation science literature, participatory action research (PAR) appears to be the only form of action research drawn on (Leykum, Pugh, Lanham, Harmon, \& McDaniel, 2009).

\section{1 | Implications for nursing}

One of the most important nursing roles is to ensure the provision of quality care using the best available evidence to underpin practice. Action research and/or in combination with implementation science framework can help to translate evidence into practice. Consequently, nurses need to be familiar with both these approaches to ensure successful application. There are many situations where action research has been used to address an emerging practice question and there are other situations where the evidence has already been created elsewhere and which now needs to be implemented in a different context.

The use of an implementation science framework within an action research approach has much to offer in this context. An important implication for nursing is the potential reduction in the research -practice time lag by taking an overarching action research approach and incorporating an implementation science framework in its structure. Furthermore, this dual use of action research and an implementation science framework also lends itself to a practice research evaluation strategy and contributes to sustainability of outcomes.

\section{3 | CONCLUSION}

Getting research evidence into practice for a more effective and sustainable healthcare service is critical for nurses. In addition, finding ways to reduce the research- practice gap is critical for patient safety, positive patient outcomes and the provision of 
optimum patient care. Therefore, implementation and evaluation should be considered in the research design as well as the inclusion of end-users. These concepts are embodied in action research. In addressing the question it appears that implementation science could benefit from the adoption of an action research process approach.

\section{CONFLICT OF INTEREST}

No conflict of interest has been declared by the authors.

\section{AUTHOR CONTRIBUTIONS}

All authors have agreed on the final version and meet at least of the following criteria [recommended by the ICMJE (http://www.icmje. org/ethical_1 author.html)]:

- substantial contributions for conception and design, acquisition of data, or analysis and interpretation of data;

- drafting the article or revising it critically for important intellectual content

\section{ORCID}

Mary Casey iD http://orcid.org/0000-0003-3305-0074

\section{REFERENCES}

Argyris, C., Putnam, R., \& Mclain Smith, D. (1985). Action science. San Francisco, CA: Jossey-Bass.

Babbie, E. (2013). The practice of social research. Belmont, CA: Wadsworth Cengage Learning.

Bailie, R., Matthews, V., Brands, J., \& Schierhout, G. (2013). A systemsbased partnership learning model for strengthening primary healthcare. Implementation Science, 8, 143.

Best, A. (2011). Systems thinking and health promotion. American Journa of Health Promotion, 25(4), eix.

Breimaier, H. E., Halfens, R. J., \& Lohrmann, C. (2015). Effectiveness of multifaceted and tailored strategies to implement a fall-prevention guideline into acute care nursing practice: $\mathrm{A}$ before-and-after, mixedmethod study using a participatory action research approach. Bio Med Central (BMC) Nursing, 14, 18

Brown, D., \& McCormack, B. G. (2011). Developing the practice context to enable more effective pain management with older people: An action research approach. Implementation Science, 6, 9.

Brydon-Miller, M. (2012). Addressing the ethical challenges of community-based research. Teaching Ethics, 12(2), 157-162.

Cassell, C., \& Johnson, P. (2006). Action research: Explaining the diversity. Human Relations, 59(6), 783-814.

Coghlan, D. (2010). Seeking common ground in the diversity and diffusion of action research and collaborative management research action modalities: Toward a general empirical method. In W. A. Pasmore, A. B. Shani \& R. W. Woodman (Eds.), Research in organizational change and development 18 (pp. 149-181). Brinkley, UK: Emerald.

Coghlan, D. (2011). Action research: Exploring perspective on a philosophy of practical knowing. Academy of Management Annals, 5, 53-87.

Coghlan, D. (2016). Retrieving the philosophy of practical knowing for action research. International Journal of Action Research, 12(1), 84-107.
Coghlan, D., \& Casey, M. (2001). Action research from the inside: Issues and challenges of doing action research in your own hospital. Journal of Advanced Nursing, 35(3), 674-682.

Coghlan, D., \& Shani, A. B. (2005). Roles, politics and ethics in action research design. Systemic Practice and Action Research, 18(6), 533-546.

Coghlan, D., \& Shani, A. B.(2017). Inquiring in the present tense: The dynamic mechanism of action research. Journal of Change Management, 17(2), 121-137.

Damschroder, L. J., Aron, D. C., Keith, R. E., Kirsh, S. R., Alexander, J. A., \& Lowery, J. C. (2009). Fostering implementation of health services research findings into practice: A consolidated framework for advancing implementation science. Implementation Science, 4, 50.

Damschroder, L. J., \& Lowery, J. C. (2013). Evaluation of a large-scale weight management program using the consolidated framework for implementation research (CFIR). Implementation Science, 8, 51.

Eccles, M. P., \& Mittman, B. S. (2006). Welcome to implementation science. Implementation Science, $1,1$.

Glasgow, R. E., \& Emmons, K. M. (2007). How can we increase translation of research into practice? Types of Evidence Needed Annual Review of Public Health, 28, 413-433.

Goodyear-Smith, F., Jackson, C., \& Greenhaigh, T. (2015). Co-design and implementation research: Challenges and solutions for ethics committees. BMC Medical Ethics, 16, 78.

Green, L. W. (2008). Making research relevant: If it is an evidence-based practice, where's the practice-based evidence? Family Practice, 25 (Suppl. 1), 20-24.

Green, L. W., \& Glasgow, R. E. (2006). Evaluating the relevance, generalization and applicability of research: Issues in external validation and translation methodology. Evaluation and the Health Professions, 29(1), 126-153.

Green, L. W., Glasgow, R. E., Atkins, D., \& Stange, K. (2009). Making evidence from research more relevant, useful and actionable in policy, program planning and practice: Slips "twixt cup and lip. American Journal of Preventive Medicine, 37, S187-S191.

Greenwood, D. (2007). Pragmatic action research. International Journal of Action Research, 3, 131-148.

Heyrani, A., Maleki, M., Marani, A. B., Ravagi, H., Sedaghat, M., Jabbari, M., ... Abdi, Z. (2012). Clinical governance implementation in a selected teaching emergency department: A systems approach". Implementation Science, 7, 84

Kirk, M. A., Kelley, C., Yankey, N., Birken, S. A., Abadie, A., \& Damschoder, L. (2016). A systematic review of the use of the Consolidated Framework for Implementation Research. Implementation Science, 11, 72

Kitson, A., Rycroft-Malone, J., Harvey, G., McCormack, B., Seers, K., \& Titchen, A. (2008). Evaluating the successful implementation of evidence into practice using the PARiHS framework: Theoretical and practical challenges. Implementation Science, 8, 1.

Latour, B. (1998). From the world of science to the world of research?. Science In Nowotny, H., Scott P. and Gibbons M., (2001). Re-Thinking Science (p. 2). Cambridge, Polity Press: Knowledge and the public in an age of uncertainty.

Levin, M. (2003). Action research and the research community. Concepts and Transformation, 8, 75-280.

Lewin, K. (1946). Resolving Social Conflicts. Washington, DC: American Psychological Association.

Lewin, K. (1997). Action research and minority problems. In K. Lewin (Eds.), Resolving social conflicts (pp. 143-154). Washington, DC: American Psychological Association. (original publication, 1946).

Leykum, L. K., Pugh, J., Lanham, H. J., Harmon, J., \& McDaniel, R. (2009). Implementation research design: Integrating participatory action research into randomized controlled trials. Implementation Science, 4 , 69.

Lobb, R., \& Colditz, G. A. (2013). Implementation Science and its application to population health. Annual Review of Public Health, 34, 235-251. 
May, C. (2006). A rational model for assessing and evaluating complex interventions in health care', BMC health services research. BMC, 6, 86.

May, C. (2013). Towards a general theory of implementation. Implement Science, 8, 18.

May, C., \& Finch, T. (2009). Implementing, embedding and integrating practices: An outline of normalization process theory. Sociology, 43(3), 535-554.

Melynk, B., \& Fineout-Overholt, E. (2011). Evidence-based practice in nursing \& healthcare: A guide to best practice ( $2 \mathrm{nd}$ ed). London: Wolters Kluwer Lippincott Williams \& Wilkins.

Morrison, B., \& Lilford, R. (2001). How can action research apply to health services? Qualitative Health Research, 11(4), 436-449.

Murphy, N. (2015). Advancing the interdisciplinary collaborative health team model: Professionalism, implementation science and therapeutic alliance to enact social justice practice. Advances in Nursing Science, 38(3), 215-226.

Nilsen, P. (2015). Making sense of implementation theories, models and frameworks. Implementation Science, 10, 53.

Nowotny, H., Scott, P., \& Gibbons, M. (2001). Re-thinking science. Polity Press, Cambridge, UK: Knowledge and the Public in an Age of Uncertainty.

Peters, D. H., Tran, N. T., \& Adam, T. (2013). Implementation research in health: A practical guide. alliance for health policy and systems research and the world health organisation. Geneva: WHO.

Reason, P., \& Bradbury, H. (2008). Sage handbook of action research: Participative inquiry and practice (2nd ed). London: Sage.

Reason, P., \& Torbert, W. R. (2001). The Action Turn: Toward a Transformational Social Science Concepts and Transformation, 6(1), 1-38.

Rycroft-Malone, J., Harvey, G., Seers, K., Kitson, A., McCormack, B., \& Titchen, A. (2004). An exploration of the factors that influence the implementation of evidence into practice. Journal of Clinical Nursing, 13, 913-924.

Rycroft-Malone, J., Seers, K., Chandler, J., Hawkes, C. A., Crichton, N., Allen, C., ... Strunin, L. (2013). The role of evidence, context and facilitation in an implementation trial: Implications for the development of the PARIHS framework. Implementation Science, 8, 28.

Sobo, E. J., Bowman, C., \& Gifford, A. L. (2008). Behind the scenes in health care improvement: The complex structures and emergent strategies of Implementation Science. Social Science \& Medicine, 67 (10), 1530-1540.

Susman, G. I., \& Evered, R. D. (1978). An assessment of the scientific merits of action research. Administrative Science Quarterly, 23, 582-601.

Thomas, A., Menon, A., Boruff, J., Rodriguez, A. M., \& Ahmed, S. (2014). Applications of social constructivist learning theories in knowledge translation for healthcare professionals: A scoping review. Implementation Science, 9, 54.

Torbert, W. R. (1991). The power of balance. Thousand Oaks, CA: Sage.

Whitehead, D. (2005). Project management and action research: Two sides of the same coin? Journal of Health Organization and Management, 19(6), 519-531.

Williamson, G., \& Prosser, S. (2002). Action research: Politics, ethics and participation. Journal of Advanced Nursing, 40(5), 587-593.

How to cite this article: Casey M, O' Leary D, Coghlan D. Unpacking action research and implementation science: Implications for nursing. J Adv Nurs. 2018;74:1051-1058. https://doi.org/10.1111/jan.13494

The Journal of Advanced Nursing (JAN) is an international, peer-reviewed, scientific journal. JAN contributes to the advancement of evidencebased nursing, midwifery and health care by disseminating high quality research and scholarship of contemporary relevance and with potential to advance knowledge for practice, education, management or policy. JAN publishes research reviews, original research reports and methodological and theoretical papers.

For further information, please visit JAN on the Wiley Online Library website: www.wileyonlinelibrary.com/journal/jan

\section{Reasons to publish your work in JAN:}

- High-impact forum: the world's most cited nursing journal, with an Impact Factor of 1.998 - ranked 12/114 in the 2016 ISI Journal Citation Reports $\odot$ (Nursing (Social Science)).

- Most read nursing journal in the world: over 3 million articles downloaded online per year and accessible in over 10,000 libraries worldwide (including over 3,500 in developing countries with free or low cost access).

- Fast and easy online submission: online submission at http://mc.manuscriptcentral.com/jan.

- Positive publishing experience: rapid double-blind peer review with constructive feedback.

- Rapid online publication in five weeks: average time from final manuscript arriving in production to online publication.

- Online Open: the option to pay to make your article freely and openly accessible to non-subscribers upon publication on Wiley Online Library, as well as the option to deposit the article in your own or your funding agency's preferred archive (e.g. PubMed). 